\title{
Is access to paediatric dental general anaesthesia by need or by postcode?
}

\author{
Helen L. Sanders ${ }^{\star 1}$ and Paul F. Ashley ${ }^{2}$
}

\section{Key points}

Explores the current picture of paediatric dental general anaesthesia services in the UK.
Discusses implications of, and challenges faced by, regional inequalities.
Offers suggestions to improve the national picture of dental general anaesthesia services.

\begin{abstract}
Children's oral health, and the number of children attending for dental treatment under general anaesthesia continue to be in the spotlight of the dental press. But are all children across the UK given the same opportunities to access comprehensive dental care under general anaesthesia? This article gives details of a recent evaluation of dental general anaesthetic services currently provided in the UK. It outlines the current picture of services, discusses the challenges and the implications of the results, and makes suggestions to help improve the regional inequalities shown by the evaluation.
\end{abstract}

\section{Introduction}

Children's oral health is a hot topic at present ${ }^{1,2,3}$ with concerns being raised about the large number of young children requiring dental general anaesthetic (DGA) for treatment. The number of children admitted to hospital for dental caries (aged 5-9 years), continues to rise (25,923 in 2016-17 to 26,111 in 2017-18). ${ }^{4}$

Reasons for this increase in hospital admissions for caries are unclear, but inequality is likely to be a major factor. School-age children from the poorest backgrounds are up to five times more likely than their better off counterparts to be admitted to hospital for dental treatment under general anaesthesia. ${ }^{3,5}$ This can also be seen in the local authority area variation in the oral health of 5-year olds, ${ }^{6}$ with deprived areas having more incidence of dental caries.

Ideally this situation is managed by prevention of dental caries and earlier restorative

${ }^{1}$ DCHS NHS Foundation Trust, Salaried Primary Care Dental Service, Derby, United Kingdom; '2Paediatric Dentistry, UCL, London, United Kingdom

${ }^{*}$ Correspondence to: Helen Laura Sanders

Email: helensanders1@nhs.net

Accepted 22 July 2019

https://doi.org/10.1038/s41415-019-0857-7 intervention. However, there will always be a proportion of children needing DGA. Effective dental treatment under general anaesthetic will improve oral health-related quality of life $\mathrm{f}^{7,8}$ and comprehensive DGA treatment (fillings and extractions) will keep the need for further dental treatment at a similar level to that in the general population. ${ }^{9}$ These services should be led by specialist or consultants in paediatric dentistry, or a dentist who can demonstrate the necessary competencies for this. ${ }^{10,11}$ Currently there are two types of DGA list commonly provided, extraction only and comprehensive care. Comprehensive care lists allow restorations and extractions to be provided. For care to be provided based on treatment need it is essential that children have access to the comprehensive care type of DGA.

Are children across the UK given the same opportunities for comprehensive care under general anaesthetic? We carried out an evaluation of services currently provided in the UK in order to determine:

1. If children had similar levels of access to DGA services

2. If children had access to comprehensive care lists

3. If DGA services were specialist/ consultant led.

\section{What is the current picture of the national paediatric dental general anaesthetic services?}

\section{Data collection}

Information was collected via email between Jan-June 2018 from the following sources:

- Clinical directors within the BDA/ CDS group

- Paediatric dental consultants working in UK dental hospitals.

The following questions were asked:

- Do you run a paediatric DGA list?

- Is it extraction only or comprehensive care or do you provide both?

- Is it specialist- or consultant-led?

Responses were anonymised so that individual hospitals or CDS services could not be identified.

\section{Survey responses}

Replies were received from a total of 26 community dental services, ten dental hospitals, four children's hospitals, and two district general hospitals. Distribution of the geographical regions covered by the respondents ranged from the Northeast of Scotland, 


\begin{tabular}{|c|c|c|c|c|c|}
\hline $\begin{array}{l}\text { Total no. of } \\
\text { respondents }\end{array}$ & $\begin{array}{l}\% \text { without access to } \\
\text { GA lists }\end{array}$ & $\begin{array}{l}\% \text { providing fully } \\
\text { comprehensive care } \\
\text { to all }\end{array}$ & $\begin{array}{l}\text { \% providing only } \\
\text { comprehensive care to } \\
\text { medically compromised/ } \\
\text { special needs children }\end{array}$ & $\begin{array}{l}\% \text { providing } \\
\text { exodontia and } \\
\text { comprehensive care }\end{array}$ & $\begin{array}{l}\% \text { providing } \\
\text { exodontia only }\end{array}$ \\
\hline 42 & 10 & 2 & 5 & 71 & 12 \\
\hline
\end{tabular}

Regions covered by responses to the survey

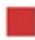

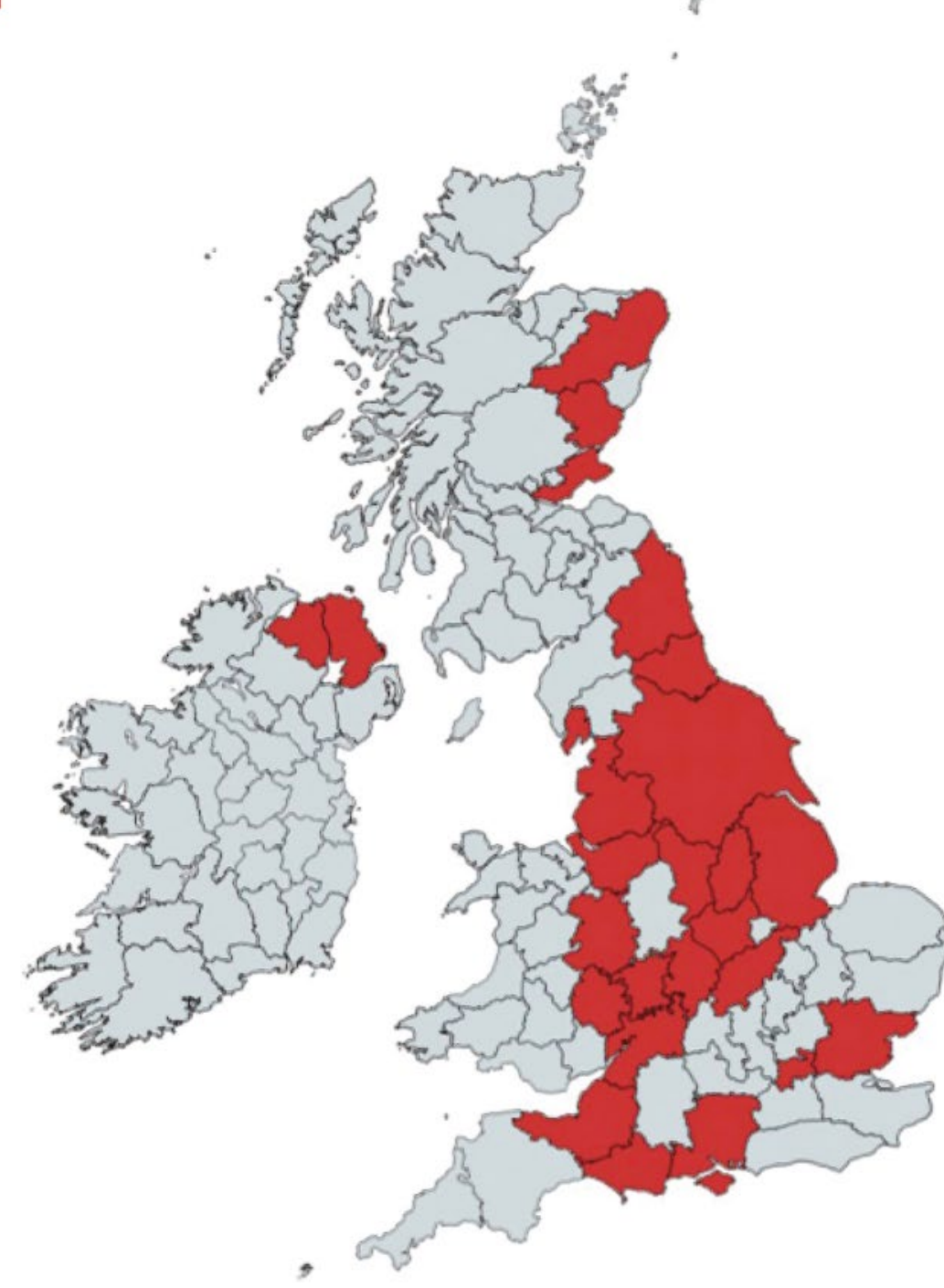

Fig. 1 Area covered by responses received. Reproduced with permission from mapchart.net

through the North and the Midlands to London in the South and covering both the west and east regions of England (Fig. 1). Unmarked areas either did not provide a response or we were unable to identify a contact to provide information on GA services provided in those areas. The area covered by the responses is highlighted in red in Figure 1. percent provided comprehensive care only. This information is summarised in Table 1.

DGA services provided by hospitals ran lists that were specialist- or consultant-led. Of the 26 community dental services that replied, only $11(42 \%)$ had access to either a specialist or consultant in paediatric dentistry to either assess and carry out treatment under DGA, or to provide advice.

\section{What are the implications of these findings?}

Within the areas surveyed we found significant variation in the type of treatment available under GA and the availability of specialists or consultants. Unrestricted access to comprehensive care under GA was only available in $73 \%$ of areas surveyed. This means that in the areas where this was not offered treatment planning will not be by need but by availability of the service which is unacceptable. This is a postcode lottery with some children disadvantaged by the area in which they live. Restorative treatment provided under general anaesthesia is more durable than that provided under LA or sedation, these children are therefore potentially being denied the most effective treatment. ${ }^{12,13}$ Furthermore, a significant proportion of services were not consultant- or specialist-led, contrary to guidance and commissioning standards. ${ }^{10,11}$

In general, data on DGAs was difficult to collect and it is clear we do not have the full picture of services across the UK. It has been suggested that a universal monitoring system for DGA should be introduced ${ }^{14}$ and that there was a need to look at national access to services, quality, and provision of services. This has not happened, and this survey highlights the urgent need for this to ensure all children have access to the same level of care.

\section{What should be done to change this?} provide any DGA services. Twelve perce only provided extractions under DGA and five percent provided restricted access to comprehensive care to children with special needs. Seventy-one percent provided both extraction only and comprehensive care, and only two
Given the increasing figures for children attending DGA, the regional inequalities in children's oral health, the postcode lottery apparent in delivering care under DGA and the 
difficulty accessing national data surrounding availability of paediatric DGA, we recommend the following:

1. Development of a national database of paediatric DGAs is needed, in order to enable audit and service evaluations, and to help plan provision of services. This has previously been suggested in the literature ${ }^{14}$ but has not yet evolved

2. Introduction of regional pathways for all children attending paediatric DGA to ensure equal access for all children. This is already being considered, both in the paediatric commissioning guide, and in the development of regional paediatric managed clinical networks

3. An increase in the number of available specialists and consultants in paediatric dentistry is required, particularly within the community dental services, as these services appear to provide a large percentage of the paediatric DGA services nationally.

\section{References}

1. Royal College of Surgeons. Press release 26 September 2018. Available online at https://www.rcseng.ac.uk/ newsandevents/media-centre/press-releases/hospitaladmissiontooth-decayl (accessed 7 October 2019).

2. Public Health England. Oral health survey of 5 -year-old children2017. May 2018.

3. British Dental Association. Press release 6 March 2019. Available online at https://bda.org/news-centre/ press-releases/postcode-lottery-of-decay-demands-real-investment-in-prevention (accessed 7 October 2019).

4. NHS. Hospital Admitted Patient Care Activity, 2017-18. Available online at https://digital.nhs.uk/ data-and-information/publications/statistical/hospital-admitted-patient-care-activity/2017-18 (accessed April 2019).

5. Mortimare A, Wilkinson R, John J H. Exploring the potential value of using data on dental extractions under general anaesthesia to monitor the impact of dental decay in children. Br Dent J 2017; 222: 778-781.

6. Public Health England. Local authority area variation in the oral health of $5 \mathrm{yr}$ olds. Available online at https://assets.publishing.service.gov.uk/government/ uploads/system/uploads/attachment_data/file/707179/ Local_authority_area_variation_in the_oral health of_five-year-olds.pdf (accessed 7 October 2019).

7. Anderson H K, Drummond B K, Thomson W M. Changes in aspects of children's oralhealthrelated quality of life following dental treatment under general anaesthesia. Int J Paediatr Dent 2004; 14: 317-325.
8. De Souza M C, Harrison M, Marshman Z. Oral health-related quality of life following dental treatment under general anaesthesia for early childhood cariesa UK based study. Int J Paediatr Dent 2017; 27: 30-36.

9. Savanheimo N, Vehkalahti M M. Five-year follow-up of children receiving comprehensive dental care under general anesthesia. BMC Oral Health 2014; 14: 154. Available onine at https://www.ncbi.nlm.nih.gov/pmc/ articles/PMC4277839/ (accessed April 2019).

10. Adewale L, Morton N, Blayney M. Guidelines for the management of children referred for dental extractions under general anaesthesia. London: Association of Paediatric Anaesthetists of Great Britain and Ireland 2011. Available online at https://www.rcoa.ac.uk/ system/files/PUB-DentalExtractions.pdf (accessed April 2019).

11. NHS England. Commissioning Standard for Dental Specialties - Paediatric Dentistry. 2018. Available online at https://www.england.nhs.uk/wp-content/ uploads/2018/04/commissioningstandardfordentalspecialtiespaediatricdentristry.pdf (accessed April 2019).

12. Tate $A$ R, Ng M W, Needleman H L, Acs G. Failure rates of restorative procedures following dental rehabilitation under general anaesthesia. Paediatr Dent 2002; 24: 69-71.

13. Eidelman E, Faibis S, Peretz B. A comparison of restorations for children with early childhood caries treated under general anaesthesia or conscious sedation. Paediatr Dent 2000; 22: 33-37.

14. Robertson S, Ní Chaollaí A, Dyer T A.. What do we really know about UK paediatric dental general anaesthesia services? Br Dent J 2012; 212: 165-167. 